\title{
ENSINO E APRENDIZAGEM DE PORTUGUÊS LÍNGUA ESTRANGEIRA (PLE): REPENSANDO O CONTEXTO DE IMERSÃO
}

\author{
Nildicéia Aparecida ROCHA* \\ Rosangela Sanches da Silveira GILENO**
}

- RESUMO: Tendo em vista a questão da mobilidade estudantil universitária, gostaríamos, neste trabalho, de refletir sobre as especificidades de se ensinar e aprender Português Língua Estrangeira (PLE) tanto em contexto de imersão como fora dele, a partir das observaçóes realizadas em dois momentos: por um lado, descreveremos um curso de PLE em situaçáo de imersão em uma universidade no interior do estado de São Paulo, Brasil; e por outro, um curso de PLE fora do contexto de imersão, em uma universidade na Espanha, em uma capital de província. Neste sentido, gostaríamos de trazer aqui uma reflexão sobre o ensino de PLE em situação de imersão e fora dela quando o tratamento didático-pedagógico parte da relação indissociável entre língua e cultura, dentro de uma abordagem comunicativa intercultural, procurando desenvolver no aprendiz uma competência comunicativa intercultural.

- PALAVRAS-CHAVE: Ensino e aprendizagem de Português língua estrangeira. Contexto de Imersão. Língua e cultura.

\section{Considerações iniciais}

O processo de mobilidade internacional promovido pelo intenso ir e vir de pessoas ao redor do mundo tem possibilitado uma importante procura por aprender e ensinar línguas estrangeiras. Essa procura é incentivada pelos órgãos governamentais e pelas políticas educativas, as quais tentam orquestrar uma atualização da denominada Torre de Babel.

Atualmente, as pessoas aprendem mais línguas do que jamais se pensou. Hoje aprender línguas é digno de status, como sempre o foi, não obstante, aprender línguas não é mais exclusividade das elites. Agora, pessoas das classes sociais menos favorecidas

\footnotetext{
* UNESP - Universidade Estadual Paulista. Faculdade de Ciências e Letras - Departamento de Letras Modernas. Araraquara - SP - Brasil. 1480-901 - nildirocha@fclar.unesp.br

** UNESP - Universidade Estadual Paulista. Faculdade de Ciências e Letras - Departamento de Didática. Araraquara - SP - Brasil. 1480-901 - rosangela@fclar.unesp.br
} 
economicamente também têm acesso ao aprendizado de línguas estrangeiras. Podemos citar como exemplo o caso de estudantes universitários que procuram aprender línguas em universidades estrangeiras por meio de programas com bolsas de estudo, como o Idioma Sem Fronteiras (IsF), desenvolvido pelo Ministério da Educação (MEC) com a colaboração da Secretaria de Educação Superior (SESu) e da Coordenação de Aperfeiçoamento de Pessoal de Nível Superior (CAPES), que tem como objetivo proporcionar oportunidades de acesso, por meio do Ciência Sem Fronteiras ${ }^{1}$ e de outros programas de mobilidade estudantil, a universidades de países onde a educação superior é conduzida em sua totalidade ou em parte por meio de línguas estrangeiras ${ }^{2}$. Convém esclarecer aqui que tais açōes são vistas como práticas sociais e educacionais promotoras do ensino e aprendizagem de línguas.

No entanto, não podemos deixar de observar que a denominada internacionalização (ZOPPI FONTANA, 2009) tem como objetivo prioritário, para os órgãos governamentais, colocar o Brasil em níveis de destaque nos rankings internacionais científicos e acadêmicos. Ademais, a questão que se pretende com tais programas, que é difundir amplamente o ensino e a aprendizagem das diversas e variadas línguas estrangeiras, é discutível uma vez que a língua inglesa ganha destaque nestas iniciativas.

Tendo em vista a questão da mobilidade estudantil universitária, gostaríamos, neste trabalho, de refletir sobre as especificidades de se ensinar e aprender Português Língua Estrangeira (doravante PLE) tanto em contexto de imersão como fora dele, a partir das observaçóes realizadas em dois momentos: por um lado, descreveremos um curso de PLE em situação de imersão em uma universidade no interior do estado de São Paulo, Brasil, no qual se tem focalizado o ensino a partir de temas culturais; e por outro, um curso de PLE fora do contexto de imersão, em uma universidade na Espanha, em uma capital de província.

Nesse sentido, o presente trabalho propõe, inicialmente, uma discussão teórica e metodológica sobre o ensino e aprendizagem em contextos de imersão e fora dele para, em seguida, apresentar o contexto institucional e pedagógico dos cursos focalizados. Em um segundo momento, passa-se a uma reflexão analítica dos dados observados, e finaliza-se com algumas questóes para serem pensadas.

\footnotetext{
1 Ciência sem Fronteiras é um programa que busca promover a internacionalização da ciência e tecnologia, por meio do intercâmbio e da mobilidade internacional. Trata-se de uma iniciativa dos Ministérios da Ciência, Tecnologia e Inovação (MCTI) e do MEC e tem como objetivos promover intercâmbio, de forma que alunos de graduaçáo e pós-graduação façam estágio no exterior; e atrair pesquisadores do exterior que queiram se fixar no Brasil ou estabelecer parcerias com os pesquisadores brasileiros nas áreas prioritárias definidas no Programa. As bolsas oferecidas são por quatro anos. Disponível em: <http://www. cienciasemfronteiras.gov.br/web/csf/o-programa>. Acesso em: 17 abr. 2015.
}

2 O Programa IsF tem como objetivo incentivar o aprendizado de línguas. Para maiores informaçôes, consultar <http://isf.mec.gov.br/>. Acesso em: 17 abr. 2015. 


\section{Foco na situação de imersão: vantagens e desvantagens}

Partimos da hipótese de que aprender uma língua estrangeira em situação de imersão pode ter uma significativa vantagem em relação a aprender língua fora da imersão. Ademais, consideramos que estar em imersáo ou fora dela pode ser determinante para o ensino com base na relação cultura e língua. No entanto, perguntamo-nos: em que sentido a situação de imersão pode favorecer o ensino e a aprendizagem na articulação entre língua e cultura?

A teoria muito tem focalizado a necessidade de se ensinar uma língua a partir da relação indissociável entre língua e cultura. Muitos estudos que abarcam o ensino da língua-cultura e das questóes interculturais estão presentes na linguística aplicada ao ensino de línguas estrangeiras (KRAMSCH, 1993; GIMENEZ, 2002; FONTES, 2003; MENDES, 2003, 2004, 2008, 2010; OLIVEIRA; FURTOSO, 2009; BUSNARDO, 2010; NIEDERAUER, 2010; SANTOS, 2010). Nota-se que nessa área de pesquisa, o número de trabalhos científicos que contemplam os aspectos interculturais no ensino-aprendizagem da língua portuguesa como segunda língua ou como língua estrangeira é cada vez maior. Grande parte desses trabalhos tem tratado de questóes relativas à educação intercultural (KRAMSCH, 1993); à abordagem intercultural (MENDES, 2008) e à competência comunicativa intercultural (BYRAM, 1997).

Kramsch (1993) atesta que o ensino da cultura envolve quatro tipos de reflexóes ou percepçóes advindos dos nativos e dos estrangeiros. Considerando que a cultura nativa $(\mathrm{C} 1)$ e a cultura estrangeira $(\mathrm{C} 2)$ pertencem a uma realidade multifacetada e multicultural, representando diferentes tipos de subculturas como as de geraçóes, profissionais, educacionais, regionais, etárias, étnicas ou de gênero, essas reflexóes podem ser expostas como:

C1: cultura nativa real.

C1': percepção do falante nativo sobre sua própria cultura.

C1": percepção do falante nativo sobre a cultura estrangeira.

C2: cultura estrangeira real.

C2': percepção do falante estrangeiro sobre a sua própria cultura estrangeira.

C2": percepção do falante estrangeiro sobre a cultura nativa do outro.

Assim, segundo Kramsch (1993), a única maneira de se construir um entendimento completo e, portanto, menos parcial do entendimento de ambas $\mathrm{C} 1$ e C2 é desenvolver uma terceira perspectiva, que capacitaria os aprendizes a considerar tanto a visão de si mesmo quanto a visão do outro em C1 e em C2. Para a autora citada, é precisamente esse terceiro lugar que a educação cross-cultural ou intercultural procura estabelecer. 
Também chamada de abordagem intercultural, inclui a reflexão sobre a culturaalvo e a cultura materna, excluindo a ideia de identidades sociais monolíticas. Seus objetivos visam à aprendizagem sobre cultura, a comparação entre culturas e à exploração do significado de cultura (REIS; BROCK, 2010, p.78).

Para aplicação de tal perspectiva, Kramsch (1993, p.210) propóe quatro etapas³:

1. Reconstruct the context of production and reception of the text within the foreign culture (C2,C2').

2. Construct with the foreign learners their own context of reception, i.e. find an equivalent phenomenon in $C 1$ and construct that C1phenomenon with its own network of meanings (C1, C1').

3. Examine the way in wich C1' and C2' contexts in part determine C1" e C2", i.e. the way each culture views the other.

4. Lay the ground for a dialogue that could lead to change.

Nesse sentido, a educação intercultural tenta transformar as barreiras culturais em pontes interculturais. Uma abordagem dialógica pode criar elos com a língua e a cultura por meio das exploraçóes entre as fronteiras interculturais criadas pela língua na construção cultural da realidade. Dentro da abordagem comunicativa, Mendes (2004) desenvolveu o conceito de Abordagem Comunicativa Intercultural como:

[...] a força potencial que pretende orientar as açóes de professores, alunos e de outros envolvidos no processo de ensino/aprendizagem de uma língua, materna ou estrangeira, o planejamento de cursos, a produçáo de materiais e a avaliaçáo da aprendizagem, com o objetivo de promover a construção conjunta de significados para um diálogo entre culturas... portanto... orienta um modo de ser e de agir, de ensinar e de aprender, de produzir planejamentos e materiais culturalmente sensíveis aos sujeitos participantes do processo de aprendizagem, em busca da construção de um diálogo intercultural (MENDES, 2008, p.60-61).

Convém salientar o que Mendes (2008) considera como intercultural são as açóes, atitudes ou práticas que incitam os alunos a valorizarem o respeito ao outro,

\footnotetext{
3 "1. Reconstruir o contexto de produção e recepção do texto dentro da cultura estrangeira C2 e percepçóes de C2'; 2. Construir com os alunos seu próprio contexto de recepçâo, isto é, encontrar um fenômeno equivalente em $\mathrm{C} 1$ e construir o fenômeno na C1' com suas próprias redes de significado; 3 . Examinar o modo como as percepçóes de C1' e C2' em parte determinam as percepçóes que estrangeiros têm delas, isto é, o modo como cada cultura vê a outra (C1" e C2"); 4. Preparar o terreno para um diálogo que poderia levar à mudança." (KRAMSCH, 1993, p.210, tradução nossa).
} 
assim como as diferenças e a diversidade cultural, construindo, desta forma, novos significados por meio da interação entre suas experiências advindas da cooperação e integração de mundos culturais por vezes diferentes. A autora apresenta três princípios norteadores da abordagem comunicativa intercultural (MENDES, 2008): o primeiro relaciona-se à alteridade, isto é, à maneira que vemos o outro e o mundo que nos cerca; o segundo dialoga com a identidade, referindo-se a como agimos no mundo e como dividimos a nossa experiência; e o terceiro é uma junção dos dois anteriores, pois expóe como nos comunicamos com o outro.

Dentro da abordagem comunicativa intercultural, torna-se necessário desenvolver uma competência comunicativa intercultural (CCI). Para Byram (1997), a competência intercultural refere-se à habilidade dos falantes se comunicarem em suas próprias línguas, com outras línguas e culturas. A competência intercultural, somada às outras competências, como a linguística, a sociolinguística e a discursiva, compóe a competência comunicativa intercultural. O conceito de competência comunicativa intercultural, segundo Byram (1997), deverá incluir os seguintes domínios: (1) atitude, definida como "curiosidade" e "abertura", prontidão para suspender uma atitude de descrédito relativamente a outras culturas e de crença na sua própria cultura. É o elemento atitude que previne o surgimento de consideraçóes de superioridade cultural face a culturas diferentes. (2) Conhecimento que está relacionado ao conhecimento dos grupos sociais, respectivas práticas e produtos, e processos gerais de interação social e individual, quer na sua própria cultura quer na cultura do interlocutor. Inclui o conhecimento das relaçóes entre as duas culturas e os estereótipos criados. (3) Competências de interpretação e de relacionamento, relativas à capacidade de interpretaçáo de eventos ou tipos de discurso de outra cultura (por exemplo, estilos de escrita), explicando-os e relacionando-os com equivalentes da sua própria cultura. (4) Competências de descoberta e de interação, isto é, capacidade de inferir conceitos e valores culturais no decurso da interação verbal com membros de outra cultura. (5) Consciência cultural crítica (educação política), isto é, capacidade de avaliar criticamente práticas e produtos culturais de ambas as culturas.

Tomando por base tais pressupostos e voltando ao nosso objeto de estudo - o ensino- aprendizagem de Português Língua Estrangeira numa abordagem comunicativa intercultural, procurando desenvolver no aprendiz uma competência comunicativa intercultural -, gostaríamos de trazer aqui uma reflexão sobre o ensino de PLE em situação de imersão e fora dela quando o tratamento didático-pedagógico parte da relação indissociável entre língua e cultura. Ou seja, partindo do ensino de PLE com base em temas culturais, estar em contexto de imersão favorece o ensino e a aprendizagem ou estar fora da situação de imersão dificulta o ensino e a aprendizagem?

Considerando as contribuiçóes da teoria de Krashen $(1982,1985)$ e Krashen e Terrel (1983), no que diz respeito à distinção entre aquisição e aprendizagem de línguas estrangeiras, podemos dizer que a situação de aquisição favorece o desenvolvimento da competência comunicativa do estrangeiro, uma vez que a aquisiçấo é produto de um 
processo subconsciente que requer interação significativa na língua-alvo, o que Krashen (1985) chama de comunicação natural, na qual os falantes estão concentrados não na forma dos enunciados, mas no ato comunicativo. Em outras palavras, a necessidade de comunicação, em situaçôes reais, provoca uma interação significativa e constante na língua-alvo. Já a aprendizagem, é um processo consciente que resulta do conhecimento formal "sobre" a língua. Através da aprendizagem (que depende de esforço intelectual para acontecer), o indivíduo é capaz de explicitar as regras existentes na língua, e isto não significa competência comunicativa, e sim competência linguística.

Para Krashen (1985), a aprendizagem nunca se transformará em aquisição e, portanto, através da aprendizagem nunca se chegará a um nível de competência comunicativa que possa ser equiparada à de um nativo, o que ocorrerá apenas se houver aquisição. A situação de aprendizagem contribuiria apenas para um discurso pouco fluido, uma vez que os alunos estariam mais preocupados com a forma do que com a mensagem a ser transmitida.

Convém salientar as críticas feitas a essa teoria no que diz respeito à falta de uma definição do termo "língua adquirida" e o não reconhecimento da "interlíngua" como fator importante dentro do processo de conhecimento de uma LE.

Calegari (2006, p. 89) também concorda que realmente há dois processos distintos no momento em que alguém entra em contato com a língua estrangeira: um no qual são internalizadas certas estruturas da língua sem que tenham sido estudadas formalmente, decorrentes apenas da exposição do indivíduo a ela (como é o caso da aquisição em situação de imersão), e outro no qual há um esforço intelectual para compreender o funcionamento da nova língua, como as regras de sintaxe ou o novo vocabulário, como é o caso da aprendizagem em contexto formal de ensino.

Sobre a teoria de Krashen, convém ainda destacar a hipótese do insumo (input). Esta hipótese tenta explicar como o aprendiz adquire uma segunda língua, ou seja, como a aquisição de uma segunda língua ocorre. De acordo com esta hipótese, o aprendiz desenvolve ou progride quando recebe insumo na segunda língua que seja um grau além de seu estágio atual de competência linguística. Assim, se o estágio atual do aprendiz é i, então a aquisição ocorre quando ele/ela for exposto a um insumo compreensível (comprehensible input) que pertença ao nível i+1. Isto vai além da escolha de vocabulário e estruturas gramaticais, mas envolve a apresentação do contexto e a negociaçáo de significados. A partir dessa hipótese, Krashen (1985) constata que as aulas seriam mais eficientes para alunos iniciantes se os alunos fossem expostos em ambientes de imersão. No entanto, a exposição à língua estrangeira somente trará benefícios ao aprendiz se contiver insumo compreensível. Portanto, nem sempre grande quantidade de insumo ou grande tempo de exposição ao input garantem bons resultados. Assim, de acordo com essa teoria, o que é mais importante para a aquisição de uma LE é que os alunos tenham acesso a uma quantidade de insumo suficiente e compreensível, uma vez que o input deve ser apresentado em contexto. Ademais, o foco deve estar na mensagem, na comunicação e não na estrutura da língua. 
Nessa mesma direção, Vygotsky (1998) em sua abordagem sócio-histórica e interacionista considera que as funçôes psicológicas superiores se constroem na interação do indivíduo com outros indivíduos e com o meio, mediatizados por instrumentos e signos. Entendemos com Vygotsky a mediação como um processo de intervenção de um elemento intermediário na relação homem/mundo. Essa mediação pode ser sistematizada na escola ou vivenciada na comunidade.

Nessa perspectiva, podemos citar Soares (2015):

Portanto, o processo de ensino-aprendizagem, é para Vygotsky uma dimensão social de grande valia. A escola tem um papel ativo, imprescindível na sociedade. Há dinamicidade no caráter da aprendizagem, o aprender causa nos indivíduos significativos processos para seu desenvolvimento psíquico. [...] $\mathrm{O}$ aprenderdesenvolver, dá-se de maneira dialética, porque há um desenrolar de circunstâncias que perpassam o indivíduo e a sociedade na sua trajetória histórico-cultural. [...] Aprendizagem se dá por imersão em ambientes culturais ou por intervenção pedagógica. E a escola é o "locus" criado para a transmissão dos conhecimentos acumulados pela humanidade, didaticamente organizados, por um educador que dirige o processo. Deverá iniciar por leituras significativas extraídas da cultura popular (como receitas, trovas, provérbios, músicas, propagandas, entre outros). Deverão ser trabalhados: a compreensão dos textos, os sistemas grafofônicos e sintáticos. O trabalho com estes sistemas permitirá que sejam trabalhadas as partes, isto é, as palavras, sílabas e letras, sempre vinculadas a outros conhecimentos e experiências anteriores.

Apesar de Soares (2015) tratar de alfabetizaçáo de adultos, consideramos que o ensino de PLE em situação de imersão pode ser articulado com a perspectiva que ela apresenta, tanto no sentido vygotskiano, no que se refere à relação intrínseca entre aprender a partir da tríade homem/história e mundo, como no caso de que aprender uma língua estrangeira quando adulto, também pode ser vista como uma aprendizagem, como no sentido de Krashen, relacionando, mesmo que subconscientemente, com a língua materna já adquirida e aprendida. Também dialogamos com o texto acima citado quanto à relevância de se ensinar a partir da cultura, mas aqui, entendemos cultura em um sentido mais amplo (popular e erudita), de acordo com Damatta (2010).

Considerando os referentes teóricos expostos, passamos a relatar os contextos de reflexão e análise.

\section{Descrição e análise dos contextos observados}

A modo de reflexão sobre as implicaçóes de se ensinar uma língua estrangeira em contexto de imersão, relacionando intrinsecamente língua e cultura na sala de aula, 
apresentaremos os contextos sobre os quais nos debruçamos, especificamente sobre ensino e aprendizagem de PLE. Os contextos são um Projeto de Extensão de PLE realizado em uma universidade no interior paulista (Brasil), em situação de imersão; e, em seguida um Curso de PLE que ocorreu no interior na Espanha, situação fora de imersão.

\section{Curso no Brasil: projeto de PLE em situação de imersão}

Visando atender ao crescente número de intercambistas, advindos de muitas universidades estrangeiras para estudar em uma universidade estadual do interior do Estado de São Paulo, Brasil, foi desenvolvido o Projeto de Extensão intitulado "Ensino de Português como Língua Estrangeira (PLE) para estrangeiros", coordenado pela Profa. Dra. Nildicéia Aparecida Rocha e com a colaboração da Profa. Dra. Rosangela Silveira Sanches Gileno.

O referido projeto propóe promover um programa de atividades sociais e linguísticas dentro e fora da sala de aula que possa integrar o aluno estrangeiro no contexto social da UNESP e da cidade e região e, ao mesmo tempo, garantir-lhe oportunidades de desenvolver habilidades linguístico-discursivas, pragmáticas, culturais e interculturais. Nesse sentido, o objetivo mais amplo é criar espaços e momentos de convivência e aprendizagem em que o aluno estrangeiro possa adquirir competência no uso do Português como língua estrangeira (PLE) na universidade e fora dela. O contexto específico refere-se a três faculdades e um instituto, e o público-alvo são os alunos intercambistas dos cursos de graduação e dos programas de Pós-graduação de quatro unidades, assim como a comunidade externa.

Estão envolvidos no projeto vários integrantes, a saber: bolsistas, voluntários, um docente coordenador e um docente colaborador. A coordenação é responsável por promover as seguintes tarefas: acompanhar o processo de ensino de PLE durante do desenvolvimento do projeto, realizado pelos bolsistas e voluntários, orientando-os e supervisionando seu percurso docente; realizar reunióes semanais com os bolsistas para discutir textos teóricos, planejar aulas e realizar reflexóes sobre o processo de ensino e aprendizagem desenvolvido pelos bolsistas e pelos alunos estrangeiros; promover debates on-line na plataforma Moodle, entre estrangeiros e bolsistas, como entre coordenador, colaborador e bolsistas; participar do processo de avaliaçáo contínua e pontual.

No que diz respeito aos bolsistas, cabem-lhes ministrar as oficinas e realizar as atividades em PLE para os estrangeiros, além de elaborar conjuntamente com o coordenador e o colaborador relatórios parcial e final. De modo geral, todo o grupo, mas, especialmente, os bolsistas e voluntários (alunos da graduação e pós-graduação em Letras) dedicam-se ao planejamento e execução das atividades sociais e linguísticas fora da sala de aula como encontros, eventos, visitas, palestras.

Metodologicamente, no projeto são desenvolvidas as seguintes atividades: 
1. Diagnóstico: entrevista inicial com os estrangeiros para saber expectativas, necessidades, interesses e conhecimentos sobre a língua portuguesa e cultura brasileira e prova escrita para avaliar habilidades de compreensão e produção discursivo-comunicativas em nível básico, intermediário-básico e intermediário avançado;

2. Formação de turmas de acordo com o conhecimento de língua portuguesa e língua de origem, seguindo os níveis de proficiência orientados pelo QECR;

3. Seleção dos bolsistas, após publicação de edital de inscrição, por meio de uma aula didática de PLE, entrevista e análise de currículo;

4. Preparação dos bolsistas, com reunióes periódicas e indicação de leitura de textos teóricos e metodológicos sobre ensino de línguas estrangeiras, especialmente de PLE;

5. Elaboração de plano de curso de PLE para estrangeiros de acordo com as indicaçóes observadas no item Diagnóstico de cada turma formada;

6. Oficinas de PLE oferecidas semestralmente, com dois encontros semanais de duas horas cada um;

7. Planejamento e realização de atividades sociais e culturais (Chácara Sapucaia, festas do Rotary, palestras, visitas a museus, eventos culturais no SESC, congressos, festas típicas da cidade, exposiçóes, etc.);

8. Reunióes semanais entre coordenadora, colaboradora, bolsistas e voluntários para discutir os textos lidos previamente e as aulas dadas e aquelas que serão ministradas, organizar a participação do grupo em eventos ou mesmo organizar eventos, entre outros temas.

Focalizando especificamente as Oficinas de PLE, objeto de nossa reflexão, o plano de curso, além de contemplar as necessidades e interesses de cada grupo, por meio de diagnósticos, propóe abordar o seguinte conteúdo programático mínimo de acordo a cada nível grupal, segundo suas especificidades:

1. Noçóes gramático-textuais: pronúncia dos sons da língua portuguesa do Brasil, assim como da região sudeste, São Paulo; formas e valores de artigos, substantivos, adjetivos, pronomes pessoais, demonstrativos, numerais, advérbios, conjugação verbal regular e formas irregulares do indicativo, subjuntivo, imperativo, gerúndio, particípio e infinitivo; introdução das formas de mecanismo de coesão e coerência descritiva, narrativa e argumentativa, etc.;

2. Práticas linguístico-discursivas: expressão e compreensão de marcas de pessoa, espaço e tempo; expressóes de gostos e opiniōes; formas ligadas à cortesia; produçấo oral e escrita de textos; aquisiçáo de vocabulário, etc.; 
3. Noçôes histórico-regionais: focalização das cinco regióes do Brasil por meio de expressóes musicais que representam a história e a cultura de cada região; audição e compreensão de músicas de cada região brasileira; apresentação de expressões idiomáticas, etc.;

4. Aspectos culturais e interculturais que representam o Brasil, tanto internamente como frente aos países estrangeiros.

Portanto, o projeto tem como objetivo propiciar aos estrangeiros ferramentas linguístico-discursivas e culturais, por meio de oficinas de PLE e atividades culturais, promovendo maior inserçáo às atividades acadêmicas dentro e fora do campus e, possibilitar a efetiva participação comunicativa dos intercambistas estrangeiros, tanto nas aulas da graduação como da pós-graduação e com os docentes e funcionários da universidade de modo geral. $\mathrm{O}$ projeto justifica-se também por sua abrangência externa e internacional, dando maior visibilidade e representatividade às açóes da universidade referentes ao ensino de PLE no Brasil.

No que se refere à questáo aqui focalizada, a situação de imersão nas aulas de PLE e sua relação entre língua e cultura, podemos ver pelo exposto anteriormente que o referido projeto parte da relação intrínseca entre língua e cultura. Portanto, todos os níveis de ensino de PLE oferecidos no projeto partem sempre de uma entrada cultural para depreender a sistematização linguística, utilizando inclusive uma variedade representativa dos diferentes gêneros textuais em língua portuguesa, entre eles: propaganda, música, vídeo, poesia, crônica, entre outros.

Observamos que como este projeto vem sendo desenvolvido desde 2012, no presente momento, apresenta uma relativa estabilidade, mesmo considerando ser o processo de ensino e aprendizagem como o momento de aprender fazendo. Mesmo assim, para os organizadores e participantes desse projeto, a situação de imersão promove o interesse do aprendiz em aprender sobre os processos culturais do Brasil, assim como tem sido desenvolvido uma perspectiva intercultural (KRAMSCH, 1993, 1998) no sentido de negociar, respeitar a língua do outro e repensar sobre a própria língua e cultura. Esta reflexão pode ser comprovada pela continuidade dos aprendizes que participam do projeto durante o curso, que em geral tem sido de 50 alunos por semestre, tendo em vista que as quatro unidades têm recebido em média 60 intercambistas por semestre.

Ademais, durante as reunióes entre a coordenadora, a colaboradora, os bolsistas e os voluntários, muitas vezes, comentava-se exatamente o destacado interesse que os aprendizes demonstram durantes as aulas com perguntas sobre aspectos históricos do Brasil, e por vezes de Portugal, sobre a formação do povo brasileiro, sobre a música brasileira ser tão diversa, sobre as diferenças étnicas e culturais encontradas no Brasil, sobre como as pessoas tratam os estrangeiros, em geral colaborando no que podem. $\mathrm{Ou}$ seja, observa-se que, estando em situação de imersão e querendo pertencer ao espaço circunscrito, espaço brasileiro, no sentido comunicativo e cultural, os aprendizes 
interrogam e se interessam também pelos aspectos culturais de modo constante durante as aulas.

Por outro lado, registramos ainda a preocupação dos aprendizes em aprender detalhadamente alguns aspectos linguísticos, às vezes com muitas inquietaçóes sobre questóes que o professor de PLE, enquanto falante nativo da língua portuguesa, ainda não havia pensado ou problematizado, mas esta é uma reflexão para outro momento.

Cabe refletir que, considerando a experiência no referido projeto, a coordenadora, ao organizar o curso de PLE na universidade estrangeira, em contexto de não imersão, não percebeu a importância de se ensinar em situação de imersão e fora dela no tratamento da inter-relação língua e cultura. Mas, a nosso ver, a situação de imersão parece ser significativa e porque não dizer determinante na ação docente e no aprender do aluno, ao delinear o conteúdo e a metodologia levados à prática na sala de aula. Desse modo, como afirma Donald Schön (1998) sobre a prática profissional, aqui refletindo especificamente sobre a prática docente:

(La práctica) profesional también incluye un elemento de repetición. Un profesional es un especialista que tiene en cuenta ciertos tipos de situaciones una y otra vez. Esto se sugiere en el modo en que los profesionales utilizan la palabra "caso" o "proyecto", "informe", "comisión", o "trato", dependiendo de la profesión. Todos estos términos denotan las unidades con las que se constituye una práctica, y revelan tipos de ejemplos de parecido familiar. Cuando un profesional experimenta muchas variaciones de un pequeño número de tipos de casos, es capaz de "practicar" su práctica. Desarrolla un repertorio de expectativas, imágenes y técnicas. Aprende qué buscar y cómo responder a lo que encuentra. (SCHÖN, 1998, p.65). ${ }^{4}$

A prática reflexiva é justamente a que transforma as açóes e que dão sentido ao processo de ensino e aprendizagem em sua dinamicidade e heterogeneidade didáticopedagógica. Assim, a prática de ser docente precisa sustentar-se sobre hábitos que se modifiquem e se reconstruam a partir da dinamicidade e da interação em cada contexto de ensino e aprendizagem autênticos.

\footnotetext{
4 (A prática) profissional também inclui um elemento de repetição. Um profissional é um especialista que leva em consideração certos tipos de situaçóes uma e outra vez. Isto se sugere o modo em que os profissionais utilizam a palavra "caso" ou "projeto", "relatório", "comissão", ou "tratamento", dependendo da profissão. Todos estes termos denotam as unidades com as quais se constitui uma prática e revelam tipos de exemplos de semelhança familiar. Quando um profissional experimenta muitas variaçóes de tipos de casos, é capaz de "praticar" sua prática. Desenvolve um repertório de expectativas, imagens e técnicas. Aprende o que procurar e como responder ao que encontra. (SCHÖN, 1998, p.65, tradução nossa).
} 


\section{Curso na Espanha: fora de imersão}

Tendo em vista a realização de um pós-doutorado na Espanha, uma das atividades proposta foi o oferecimento de cursos de PLE à comunidade acadêmica da universidade onde foi realizada a pesquisa, com o objetivo de divulgar a língua portuguesa e a cultura brasileira.

Nesse contexto, foram oferecidos dois cursos de PLE. O primeiro curso de PLE, intitulado "Curso de Português para principiantes - Básico (A $\left.1^{5}\right)^{\text {", }}$ propunha uma primeira aproximação à Língua Portuguesa e Cultura Brasileira. Esse curso teve uma carga horária de 26 horas, distribuídas em dois encontros semanais de 2 horas cada.

Houve uma procura interessante pelo curso. Assim, em poucos dias, tivemos 30 inscritos, sendo alunos universitários espanhóis de várias regióes da Espanha, alunos universitários italianos, uma grega, uma colombiana e uma polonesa, também intercambistas estrangeiros.

O que havia em comum entre os alunos do curso de português é que a maioria era estudante do curso de Filologia em Espanhol ou uma Língua Estrangeira, como Espanhol Língua Estrangeira (doravante ELE) ou alemão, estudantes do Mestrado em ELE e outras línguas estrangeiras. De modo geral eram professores de espanhol e de literatura já formados e atuantes na universidade e na rede pública de ensino, realizando doutorado na referida universidade. Portanto, havia um grupo composto pela heterogeneidade, mas com o aspecto comum de serem da área de Letras.

Ainda sobre o perfil do grupo, ressalto que os alunos apresentaram um conhecimento prévio variado de português, mas em geral iniciante, alguns tinham um pouco de conhecimento da variante falada em Portugal (e gosto pelo Fato, estilo de música portuguesa) e apenas duas alunas, uma italiana e uma colombiana, tinham conhecimentos da língua portuguesa falada no Brasil, por terem amigos brasileiros ou como no caso da colombiana, ter estudado português do Brasil enquanto estudava na Colômbia.

Com relação ao tratamento do conteúdo programático, foi proposto inicialmente focalizar a língua sob três perspectivas, mas sempre de modo articulado, sendo:

5 O nível A1 refere-se à classificação dos alunos iniciantes, de acordo ao Quadro Europeu Comum de Referência para línguas (QECR). 
1. Noçóes gramático-textuais:

- pronúncia dos sons da língua portuguesa do Brasil;

- formas e valores de artigos, substantivos, adjetivos, pronomes pessoais e possessivos, demonstrativos, numerais, advérbios, conjugação verbal regular e formas irregulares do indicativo, imperativo;

- introdução das formas de mecanismo de coesão e coerência descritiva, narrativa.

2. Práticas linguístico-discursivas:

- expressão e compreensão de marcas de pessoa, espaço e tempo,

- expressóes de gostos e opinióes;

- formas ligadas à cortesia;

- produção escrita e oral.

3. Aspectos culturais:

- conhecimento da diversidade cultural brasileira;

- regiōes do Brasil: formação e expressividades culturais;

- reconhecimento dos aspectos interculturais.

Metodologicamente, pretendíamos trabalhar os conteúdos articulando-os, como dito anteriormente, mas partindo sempre dos aspectos culturais, ou seja, pretendíamos apresentar primeiro cada regiáo brasileira, tanto seus aspectos históricos quanto culturais, dos quais depreenderíamos as questôes de língua, estruturalmente e dentro do nível proposto, A1. No entanto, tal proposta não teve muita aceitação pela maioria do grupo.

Vale salientar que tínhamos como pressuposto a experiência anterior nos cursos de PLE no Brasil (relatado anteriormente), portanto em situação de imersão, a qual havia sido construída na base, teórica e empiricamente, de que: 1) ensinar língua se dá enquanto se adquire/aprende e reflete reciprocamente sobre a cultura do povo que fala essa língua; e, especificamente, ensinar português para hispanofalantes pressupóe um trânsito possível entres essas línguas tanto pela proximidade entre estas, tendo em vista a origem latina, quanto pela resposta positiva no ensino e aprendizagem, observado no Projeto de Extensáo de PLE descrito. Entretanto, esta premissa teve que ser desconstruída, pois os alunos demandaram foco na estrutura da língua e não nos aspectos culturais. Ressalva-se que tomamos o cuidado de apresentar textos para iniciantes na aprendizagem de português como língua estrangeira, isto é, com textos possíveis a compreensão em nível A1. 
Com relação mais especificamente ao trabalho com os aspectos culturais, de modo geral, houve uma resistência, pois o interesse verbalizado era aprender os aspectos linguístico-comunicativos e não culturais. Este interesse fez-nos repensar nossa prática docente, pois entendíamos teórica e metodologicamente que aprender uma língua é aprender como o povo dessa língua expressa comunicativa e discursivamente sua cultura, em sua complexidade cultural, geográfica e histórica. Tal observação pode ser corroborada pelo número de inscritos que tivemos inicialmente 30 (trinta), sendo que apenas 12 finalizaram o curso, e destes somente 3 continuaram o nível 2 do curso de português, justamente os que tinham interesse na literatura e cultura lusófonas e alunos de doutorado.

Por outro lado, quando havia interesse nas questôes culturais, esse se dava mais com relação à cultura portuguesa do que necessariamente brasileira, talvez pela proximidade geográfica, histórica e econômica com Portugal. Exceto as seguintes alunas: uma italiana com conhecimento prévio em português e variedade brasileira, a colombiana e a grega, que se mostraram encantadas pelo Brasil, pela língua e culturas brasileiras.

Desse modo, no sentido de ressignificar a prática docente e possibilitar a aprendizagem de PLE no curso em situação de não imersão, a docente teve que redefinir sua prática e desconstruir uma "crença" empírica, voltar-se para a teoria e verificar que a análise de dados sociais, históricos e culturais são norteadores e/ou determinantes no processo de ensino e aprendizagem, especificamente no que se refere ao ensino de PLE fora de imersão em seu ensino a partir da inter-relaçao língua e cultura.

\section{A modo de conclusão}

Retomamos nossa pergunta inicial: ensinar língua estrangeira em situação de imersão pode trazer benefícios à aprendizagem e ensino na inter-relaçao língua e cultura? De fato, verificando os contextos apresentados, de acordo com os referentes teóricos expostos aqui, podemos esboçar alguns gestos de leitura sobre a situação de imersão:

- a aprendizagem de PLE está propiciando o desenvolvimento da competência intercultural aos aprendizes vinculados ao Projeto de Extensão apresentado, pois de fato há continuidade desses aprendizes nas oficinas e atividades culturais, além de continuamente seguirem em contato via online com os bolsistas, voluntários, colaborador e coordenador do projeto;

- o ensino de PLE tem corroborado com os estudos sobre metodologia de línguas no sentido de que é vantajoso o ensino de língua a partir de sua relação intrínseca com a cultura de quem fala a língua, portanto, confirma os estudos teórico-metodológicos da área de ensino e aprendizagem de língua estrangeira.

Entretanto, com relação ao curso de não imersão, podemos inferir pelas observaçóes até agora realizadas que: 
- na aprendizagem de PLE, por não entenderem linguística e comunicativamente os textos (diversos gêneros textuais) que tematizavam a cultura brasileira ou por não terem motivação ou por não termos semelhanças históricas como os países da América Latina, os aprendizes de PLE não demonstram interesse em aprender PLE, variedade brasileira;

- no ensino de PLE é necessário realizar um estudo detalhado do contexto de ensino e aprendizagem a ser inserido, assim como uma análise dos perfis dos aprendizes, confirmando também as contribuiçóes teóricas da área.

Talvez justamente pela distância geográfica e histórica entre Europa e América há maior distanciamento também na aprendizagem e, portanto no ensino de português a falantes de espanhol. Entretanto, os hispano-americanos têm demonstrado interesse muito significativo na aprendizagem de PLE e, portanto o fazer docente, a prática do professor, tem sido outra.

Sabemos que muitos fatores podem ter sido detonantes do pouco interesse na continuidade do curso, tais como falta de motivação individual, histórias de países diferentes, interesses políticos econômicos diferentes, entre outros, fatores que poderiam contribuir para desenvolver a aprendizagem de PLE, numa perspectiva cultural e intercultural. Entretanto, no curso fora da imersáo, considerando a postura dos alunos de náo interesse pela cultura brasileira e, portanto, pela nossa história, percebemos que o interesse em aprender língua portuguesa falada no Brasil na Europa ainda é muito reduzido ou que a perspectiva didática intercultural está longe de ser uma realidade no ensino de línguas de modo mais amplo.

\section{TEACHING AND LEARNING PORTUGUESE FOREIGN LANGUAGE (PFL): RETHINKING THE CONTEXT OF IMMERSION}

- ABSTRACT: Considering the issue of university student mobility, we would like, in this work, to reflect on the specific aspects of teaching and learning Portuguese Foreign Language (PLE) in both immersion context and outside, from the observations made in two stages: by first, we describe a course of PLE in immersion situation at a university in the state of São Paulo, Brazil; and second, a course of PLE outside the immersion context, at a university in Spain in a provincial capital. In this regard, we would like to bring a reflection on the PLE teaching in immersion situation and beyond when the didactic and pedagogical treatment of the inseparable relationship between language and culture, within an intercultural communicative approach, seeking to develop in the learner a communicative competence intercultural.

- KEYWORDS: Teaching and learning Portuguese foreign language. Context immersion. Language and culture. 


\section{REFERÊNCIAS}

BUSNARDO, J. Contextos pedagógicos e conceitos de cultura no ensino de línguas estrangeiras. In: SANTOS, P.; ALVAREZ, M. L. O. (Org.). Língua e cultura no contexto de português língua estrangeira. Campinas: Pontes, 2010, p.07-10.

BYRAM, M. Teaching and assessing intercultural communicative competence. Clevedon: Multilingual Matters, 1997.

CALEGARI, M. O. V. Reflexôes sobre o modelo de aquisiçáo de segundas línguas de Stephen Krashen: uma ponte entre a teoria e a prática em sala de aula. Trabalhos em Linguística Aplicada, Campinas, v.45, n.1, p.87-101, jan./jun. 2006.

DAMATTA, R. Relativizando: uma introdução à antropologia social. Rio de Janeiro: Rocco, 2010.

FONTES, S. M. Um lugar para a cultura. In: CUNHA, M. J. C.; SANTOS, P. (Org.). Tópicos em português língua estrangeira. Brasília: Ed. da UnB, 2003. p.175-181.

GIMENEZ, T. Eles comem cornflakes, nós comemos pão com manteiga: espaços para reflexão sobre cultura na aula de língua estrangeira. In: ENCONTRO DE PROFESSORES DE LÍNGUAS ESTRANGEIRAS, 10., 2002, Londrina. Anais... Londrina: APLIEPAR, 2002. p.107-114.

KRAMSCH, C. Language and culture. New York: Oxford, 1998.

Context and culture in language teaching. Oxford: Oxford University Press, 1993.

KRASHEN, S. The input hypothesis: issues and implications. 4.ed. New York: Longman, 1985.

Principles and practice in second language acquisition. Oxford: Pergamon, 1982.

KRASHEN, S.; TERRELL, T. D. The natural approach: language acquisition in the classroom. Oxford: Pergamon, 1983.

MENDES, E. Por que ensinar língua como cultura? In: SANTOS, P.; ALVAREZ, M. L. O. (Org.). Língua e cultura no contexto de português língua estrangeira. Campinas: Pontes, 2010. p.53-78.

Língua, cultura e formação de professores: por uma abordagem de ensino intercultural. In: MENDES, E.; CASTRO, M. L. S. (Org.). Saberes em português: ensino e formaçáo docente. Campinas: Pontes, 2008. p.57-77.

Abordagem comunicativa intercultural: uma proposta para ensinar e aprender língua no diálogo de culturas. 2004. 316f. Tese (Doutorado em Linguística Aplicada)-Universidade Estadual de Campinas, Campinas, 2004. 
Aprender a língua, aprendendo a cultura: uma proposta para o ensino de português língua estrangeira (PLE). In: CUNHA, M. J. C.; SANTOS, P. (Org.). Tópicos em português língua estrangeira. Brasília: Ed. da UnB, 2003. p.185-199.

NIEDERAUER, M. E. F. Estranhamentos culturais em sala de aula de português para estrangeiros. In: SANTOS, P.; ALVAREZ, M. L. O. (Org.). Língua e cultura no contexto de português língua estrangeira. Campinas: Pontes, 2010. p.101-121.

OLIVEIRA, E. V. M.; FURTOSO, V. B. Buscando critérios para avaliação de livros didáticos: uma experiência no contexto de formaçáo de professores de português para falantes de outras línguas. In: DIAS, R.; CRISTÓVÃO, V. L. L. O livro didático de língua estrangeira: múltiplas perspectivas. Campinas: Mercado de Letras, 2009. p.235-263.

REIS, K. C.; BROCK, M. P. S. Inter-relação cultura e língua para professores de língua inglesa. Revista Perspectiva, São Paulo, ano 128, n.34, p.73-88, dez. 2010.

SANTOS, C. A. B. Orientaçóes culturais para o ensino de português como segunda língua (PSL) direcionado a estudantes dos Estados Unidos. In: SANTOS, P.; ALVAREZ, M. L. O. (Org.). Língua e cultura no contexto de português língua estrangeira. Campinas: Pontes, 2010. p.141-160.

SHÖN, D. La formación de profesionales reflexivos. Barcelona: Paidós, 1998.

SOARES, C. S. L. Contribuiçóes da teoria de Vygotsky para a alfabetizaçáo de adultos. Disponível em: <http://alb.com.br/arquivo-morto/edicoes_anteriores/anais15/alfabetica/ SoaresConceicaodeSouzaLicurgoSoares.htm>. Acesso em: 20 abr. 2015.

VYGOTSKY, L. S. A formaçáo social da mente. São Paulo: Martins Fontes, 1998.

ZOPPI FONTANA, M. (Org.). O português do Brasil como língua transnacional. Campinas: RG, 2009. 
